\title{
SOFTWARE QUALITY CERTIFICATION: IDENTIFYING THE REAL OBSTACLES
}

\author{
Megan Baker \\ Department of Business Management, Faculty of Business and Economics \\ Anne Rouse \\ Deparment of Information Systems. Faculty of Computing and Information Technology \\ Monash University, 900 Dandenong Road, Caulficld East Vic 3145. Australia
}

\begin{abstract}
A case study of software certification reveals the real difficulty of certifying quality beyond superficial assessment readers are invited to form their own conclusions.

AS 3563 Software Quality Management System is the Australian version of ISO 9001 , developed specifically for the software industry. For many Australian software houses, gaining certification with AS 3563 is a priority since cerification has become a prerequisite to doing business with government deparments and major corporations. However. the process of achieving registration with this standard is a lengthy and resource intensive process, and may have little impact on actual software quality. This case study recounts the experience of the consulting arm of one of Australia's accounting firms in its quest for cenification. By using a number of specific management strategies this company was able to successfully implement AS 3563 in less than half the time usually taken to achicve certification - a feat for which its management should be congratulated. However, because the focus of the project was on gaining certification, few intemal benefits have been realised despite the successful implementation of the standard.
\end{abstract}

\section{INTRODUCTION}

\section{Background}

Since 1 January 1994, Australian government departments and agencies have been entitled to ask information technology suppliers to provide evidence that their organisations have in place quality management systems. In 1988 the Standards Association of Australia released for publication Australian Standard 3563 Software Quality Management System (AS 3563), which was specifically designed to cater for the software industry in Australia. More recently, the 1991 release of AS 3563 included guidelines that give practical examples of the implementation of a quality management system.

AS 3563 is based on ISO 9001 Quality System - Model for Quality Assurance and Design/Development. Production, Installation and Servicing. To achieve certification with AS 3563, organisations are evaluated in light of the standard's requirements, their own documented procedures, and documented evidence proving adherence to these procedures. Examples of the areas which are addressed by AS 3563 include contract review; design control; document control; purchasing; product identification and traceability; inspection and testing; storage, packaging and delivery; training; servicing; and control of the development environment.

The government edict of 1992 galvanised the Australian information technology industry into action. For many organisations, gaining the 'quality stamp of approval' has become a major priority because of the associated market implications (Zampetakis, 1994). This process is usually costly and time consuming. Yet by using effective implementation strategies, it is possible to reduce the timeframe quite considerably.

This paper examines the implementation experience of one of Australia's accounting firms which obtained certification within a relatively short timeframe. The first part of the paper reviews two particular problems encountered, and the management techniques used to overcome these difficulties. This section is followed by a discussion on the management strategies used to actively foster the rapid procurement of AS 3563. The final section discusses the major challenge currently faced by the organisation - maintaining on-going commitment to the quality system, despite the apparent weaknesses inherent in the standard. The paper concludes by summarising the strategies which helped the organisation achieve certification, and by making recommendations for the future evolution of AS 3563.

\section{THE CERTIFICATION EXPERIENCE}

The company on which this study was based was selected as an appropriate organisation for research because of its position as one of the leaders of the information technology industry. Its success in gaining certification within the short timeframe was also an important factor. The organisation has branches in all capital cities in Australia. The division within the office in which this study was based consists of approximately 180 employees. Interviews were carried out with the quality managei responsible for the overall certification effort, and with a senior consultant who was involved with and affected by the certification effort. Interviews were 
also held with a former manager who had been heavily involved in establishing certification, and with a representative of Standards Australia. Questions were developed based on a model developed by du Pont de Nemours and Company (Hockman, Grenvilie \& Jackson, 1994) for registration with ISO 9000. Interview conclusions were submitted to all interviewees, and feedback invited, to ensure validity.

The decision to gain certification at the company was made when top management realised its potential for competitive advantage. Consequently considerable resources were then invested in appointing a full time quality manager, hiring an external quality systems consultant, and providing training for all affected staff. Internal audits were carried out to analyse existing routine work practices and written procedures. An implementation plan was created to develop new work practices where the analysis revealed the potential for improved work flows. Written procedures were either created or updated to reflect these changes. Individual project leaders developed quality plans for individual projects; the quality manager developed a quality manual which described the management, structure, policies and principles by which the organisation manages quality. A certifying organisation was chosen. Even before the days of pre-assessment and registration, management reviews were carried out to determine the status of quality related projects, internal audit results, and adherence to quality plans to evaluate the effectiveness of the new system. Further finetuning took place after the day of pre-assessment, when the organisation underwent a 'dry-run' investigation by external auditors. On the two days of certification assessment, the organisation was visited by a team of auditors from Standards Australia, which rigorously investigated the software quality management system in light of the requirements of the standard. Some minor non-conformances were reported, but the recommendation was made that registration be allowed to proceed on the condition that a plan be developed to correct these discrepancies.

The organisation gained AS 3563 registration with Standards Australia in August 1993, and recertification with the National Association of Testing Authorities (NATA) in April 1994. The initial certification with AS 3563 took just less than eight months. The average time to gain certification is eighteen months (AIIA, 1993).

Although the organisation has achieved certification, it cannot afford to rest. To maintain certification, the organisation must undergo compliance audits at regular intervals. Since $10 \%-12 \%$ of organisations fail the compliance audits these can by no means be regarded as a fait accompli.

\section{Implementation Issues}

\section{Challenges faced}

To achieve certification within eight months, the organisation had to overcome two main challenges. The chief of these related to generating staff commitment to the software quality management system. The audits held on the days of pre-assessment and certification were the other major hurdle.

\section{Gaining staff commitment}

Gaining staff commitment to AS 3563 was essential to the success of the process. This was a particular challenge, according to the quality manager, because of the staff's perception of the numerous weaknesses of the standard itself. These will be discussed later in the paper. Yet despite the perceived weaknesses of the standard, the organisation did gain considerable commitment from both its staff and management to the certification process. Senior management recognised the immediate competitive advantage, and the ongoing competitive necessity, to be gained by certification. Tremendous amounts of energy were thus channelled into gaining certification. The quality manager was given access to the necessary resources to help the organisation gain certification. It was also communicated very strongly to staff that gaining certification was immensely important for the ongoing well-being of the organisation. This is reflected in the words of one interviewee who said "We recognised the need to gain certification, and were working hell for leather trying to get it". Because of this strongly communicated message, staff worked very hard at meeting the established goals, even though many of the processes seemed irrelevant. Managers and project leaders also contributed to the certification process by releasing their staff to attend training sessions.

\section{Pre-assessment and certification}

Careful management of the third party audits carried out on the days of pre-assessment and certification was also critically important. In order to audit a company's procedures within a few hours over a couple of days, the registers of the certifying body require the organisation to be able to lay its hand on relevant documentation almost instantaneously (effective filing and document management are part of the quality system). This is a particularly intensive activity, not only for the quality manager, but for all those responsible for maintaining 
procedural documentation. Requests for proof of documentation and adherence to the standard are made at a rapid pace. At the organisation, the requests of the certifying body seemed, at times, to take on the form of a Spanish inquisition, putting those at the receiving end under considerable stress. It also put staff in a defensive position from which it was very difficult to recover.

The quality manager found the best way to handle this situation was to become pro-active. After the experience of the pre-assessment audit, he determined that for the actual certification audit he would take the initiative from the very first. By using this tactic he was able to control, to some extent, the direction of the audit. While the assessors still had set criteria to cover, controlling the agenda in this manner removed some of the stress from the review process. This approach was commented on favourably by the certifying body since the quality manager's fifteen minute presentation saved them considerable questioning time. Another tactic used to ease the tension was having refreshments available to create a relaxed environment in which the organisation's staff could interrelate on a more personal level with the external auditors. There was also one occasion when the timely aid of a senior manager helped to negotiate the situation when the inspection had begun to resemble an inquisition.

\section{Management strategies to facilitate certification}

Gaining staff commitment through management support and a pro-active attitude were two strategies which contributed greatly to the rapid attainment of certification. Other factors which were essential to the successful implementation of the quality system were the efforts of a dedicated champion and an experienced mentor; communication and training; and the use of a pilot scheme to demonstrate the quality system to the wider organisation.

\section{The use of a champion}

Within the information technology field, a champion - a person who will battle great odds in order to see his or her vision in place - is often crucial to the success of an individual project. This person has a concept of the end result, and gets it implemented by obtaining funding, pushing the project over hurdles, putting his or her reputation on the line, and by generally taking on the risk of the project. At the organisation, the role of champion was assumed by the quality manager, who took on the responsibility of organising resources, communicating progress, disseminating information, and generally working on generating commitment to the certification process. Up to gaining certification, this was a full time job - one that frequently went beyond standard working hours, and as part of the national role, involved flying to other major cities to advise and assist quality managers from other offices. This role was particularly stressful, with deadlines constantly approaching and major hurdles having to be jumped repeatedly. Despite these difficulties, the quality manager's dedication and strength of commitment were key elements in persuading employees that certification, with all its bureaucratic overtones, was indeed a worthwhile goal.

One of the key techniques employed by the quality manager in his role of champion was the use of checklists and reports which provided evidence to top management of the constant progress being made towards certification, and later, enabled the organisation to pass the on-going compliance audits. After each audit, the quality manager prepared a report of activities to be completed for the next audit (including a description of the problem, the necessary action, the person to take corrective action, and a time frame) and personally followed these up. Summaries of activities completed were circulated thoughout the organisation. This reporting activity served to keep the certification process in the forefront of the minds of management and staff.

\section{The use of a mentor}

Another individual who was a key player in the successful achievement of certification was the quality systems consultant, who took on the role of mentor. The consultant had many years of experience with the implementation of standards, and so the organisation was able to capitalise on this knowledge to effectively prepare itself for the assessment days. When the consultant was first employed, he brought with him a particularly comprehensive checklist which related to the AS 3563 requirements. By working through this set of questions, and ensuring that a positive response (along with an explanation) could be provided for each, the organisation was able to judge its preparedness for the external auditors. The consultant's prior experience ensured that the organisation knew the areas on which the auditing parties were likely to concentrate. 


\section{Communication and training}

Open communication was another key element in the successful attainment of certification. The organisation already had in place a number of communication channels, since within a consulting firm, employees rely heavily on the experiences of other staff members. Information on AS 3563 was transmitted through face-toface meetings, the telephone and electronic mail. Information was also disseminated in training courses. In addition, at the fortnightly managers' meeting which all senior consultants attend, the quality manager provided an update on initiatives and progress in regard to the quality movement. An electronic Lotus Notes database, accessible by all staff, was established to contain all the quality manuals and standards.

\section{The use of a pilot project}

One of the most effective techniques employed by the organisation to demonstrate the certification process to all staff was the use of a pilot project. A small information technology project was chosen shortly after a relevant set of methodologies had been developed. The project leader applied the methodologies to the project, established the relevant controls and produced a quality plan (all part of the requirements of AS 3563). As the project itself was relatively undemanding, it enabled the project team to concentrate on carrying out the methodology to the very letter. External auditors were even brought in so that the project team could fully experience the entire standard compliance environment. At the completion of the project the project leader shared his experience with the rest of the organisation, describing the additional activities imposed by AS 3563, the ramifications of doing the job with quality procedures in place, and the types of questions that could be expected from the auditors. As a learning exercise and demonstration for the rest of the firm this model project was highly successful. One interviewee reported that the pilot project significantly changed "...people's knowledge of what was involved, and what they had to do."

\section{Future Challenges for the Organisation}

Gaining certification is a necessary part of the AS 3563 process. From this point, however, the critical issues are maintaining certification, and embedding the quality system into the everyday activities of the organisation so that maximum benefit can be gained from the investment.

\section{Maintaining commitment}

At the organisation, while top management support was clearly evidenced by the amount of time and resources that were channelled to obtaining certification, it appears the resources were all pointed to gaining certification, and not necessarily to the underlying quality management system. While senior management "....wanted certification [and] so would do anything to make it happen", it was also pointed out that: "...the commitment [was] to getting standards national around Australia". With regard to momentum, once certification was achieved "...well, it dropped off as far as top management was concerned...it was up to the quality manager to really keep driving management."

It appears that once certification was achieved, many staff heaved a collective sigh of relief - a fairly common reaction after the stresses of the certification process. Sakovsky (1994) reports that top managers tend to believe that with certification gained, all of the work for the organization is completed; with the major hurdle passed, there is an opportunity to relax. One specific example of this at the organisation is the number of people being released to attend training courses. The quality manager reports that before certification, quality system courses would be fully booked out; once certification was gained, it became difficult to persuade managers to spare staff to attend these courses. "The partners are reluctant to send them here because it is costing them money, I mean, losing charge-out time, and the cost of the air fares for interstate staff. But they think, now that we have certification, why do we have to spend so much time and money on it?".

Since gaining certification, steps have been taken to counteract this attitude towards certification by incorporating the issue of quality into the annual planning process. The quality audit program and the summaries of the audits are now part of the agenda of National Information Technology Quality Board meetings. Thus it appears that while the necessity of certification was recognised as a major competitive tool because of the implications for market position, the underlying issue of quality (the raison d'etre for the initial development of AS 3563) was seen, for a while, to be an issue quite separate from that of certification. Once certification was gained, commitment to maintaining the same level of activity in regard to AS 3563 appeared to 
decrease quite rapidly before executive managers took action to place the quality issue, quite literally, back on the agenda.

In Australia, there is a growing recognition that to achieve high quality information systems, it is necessary to go beyond the quality assurance process (Rouse \& Watson, 1994). The organisation has also recognised the necessity of looking beyond the requirements of AS 3563 to ensure quality is part of its overall culture.

\section{Obstacles in the path of on-going commitment}

The difficulty of generating on-going commitment to the activities required by AS 3563 certification may be related to the fact that apart from the marketing advantage to be gained through certification, few benefits appear to have been realised. Certification can supposedly assist in terms of software quality, and improvement in the use of software development resources through more effective and efficient work practices. An evaluation of the benefits to be gained from certification was not the focus of this research. Nonetheless, some inferences will be made in the following section as to why the organisation did not achieve the benefits that are often touted in relation to certification.

\section{Weaknesses of AS 3563}

In many ways, the standard itself was not seen to be relevant to the needs of the organisation. The following weaknesses were referred to repeatedly throughout the interviews conducted.

Firstly, AS 3563 was designed for large projects which use traditional systems development life cycle methodologies. In many ways AS 3563 is not suited to the newer development methodologies such as clientserver, fast-tracking and rapid application development (Thomsett, 1993). These form some 70\% of the organisation's development work. These methodologies are particularly results oriented, and concerned with getting prototypes in front of the customer so rapid feedback can be gained. They are designed so that short cuts can be taken and new development routes taken as customer requirements demand. Standards, on the other hand, impose control and structure; they actually restrict developers to written company work practices Secondly, the organisation also offers services in the areas of software package evaluations, outsourcing, software maintenance, and the development of strategic plans, all of which involve little development work. Even though these services do not relate specifically to software development, because the department had gained certification, all its work process, rather than just the software development jobs, had to be carried out in line with the standard.

Thirdly, the internal audit process was viewed as onerous since considerable effort was required to maintain the auditing level. The non-conformances recorded were often regarded as trivial bureaucratic problems, with the associated follow up work being difficult to justify. Examples of non-conformances which the organisation was asked to rectify by the certifying body included out-of-date lists of staff members who had attended training sessions, and incomplete records relating to work practices such as document control (Smic-Batanic, 1994). In many cases, quality work was carried out as "catch up" work, rather than being part of day-to-day work, thus adding to project overheads.

Fourthly, the preparation of quality plans for individual projects as a major overhead. This preparation was very time consuming, taking up a considerable portion of the resources allocated to projects, with the benefits being difficult to quantify. Particularly for smaller projects, the associated administrative requirements were often seen as out of proportion in relation to the actual development work being performed.

There was also the perception among staff that the process of certification was not directly related to the quality of the product being presented to clients. At no stage were the audits, internal or external, related to the organisation's products or services provided to its customers. Thus the process of certification appeared to have little to do with the ultimate aim of AS 3563 - an improved software product.

Another problem was that the majority of procedures and methodologies had already been tried, proven and documented for many years prior to the current push for certification. In many cases, the specifications of AS 3563 certification simply required staff to prove that they were already following existing procedures.

The final issue is that certification is extremely costly and resource intensive. It is debatable whether the few process improvements identified warranted the costs of a full time quality manager, a consultant, support personnel, registration fees, training courses, travelling costs, and the loss of chargeable hours of those attending the courses. 


\section{Getting the Most from Certification}

To date at the organisation, the audits, both internal and external, have related strictly to processes. To obtain long term benefits, management may therefore need to apply the auditing process not only to those procedures which relate directly to AS 3563 , but to extend it to those issues which are directly related to business health.. These include issues such as customer levels of satisfaction, pricing, market penetration, and product and service quality. This will increase the relevance of AS 3563, and in turn generate commitment to the ongoing software quality management system. The audit results can then be used by management to develop meaningful business corrective action.

This results-oriented approach was adopted by Australian organisations studied by von Hellens (1994). Having found that the software quality management system was offering few tangible results, management within one organisation decided that "...the focal point of the quality management system implementation should move from primary software development activities to the more intangible tasks of product or service delivery" (von Hellens 1994, p 485). Another organisation explored new ways of describing the intangible nature of quality to make it more tangible and better appreciated by staff. This was achieved by involving development staff with service tasks so that they would become more aware of the relationship between customer needs and the quality process. Quality became something "...the development team could incorporate in their working practices" (von Hellens, 1994, p 485).

AS 3563 audits would then be treated as an improvement tool to be used not only to gain compliance with a standard, but also to improve business functions and business problems. The system would work to improve the business, and not just to satisfy AS 3563 requirements.

\section{CONCLUSION}

What are the lessons that can be learnt from the this organisation's experience?

Firstly, it is possible to achieve certification in a timeframe much less than the average of eighteen months. This is possible through focused management commitment; a dedicated individual championing and directing the certification process; the use of a knowledgeable consultant; open and pro-active communication on the subject of certification; training; and a pilot project to demonstrate the certification process to the wider organisation.

Secondly, the rapid procurement of AS 3563 may come at a cost. A timeframe of eight months, while it allowed sufficient time for the organisation to demonstrate adherence to the requirements of the standard and gain 'the quality stamp of approval', was insufficient time to develop lasting organisational change, and put in place structures that enabled the consideration of the wider business issues beyond those procedures required by the standard.

The initial emphasis on gaining certification at the expense of the underlying quality principles had serious implications for the ongoing commitment of staff to the software quality management system. One respondent commented that "The perception, held by many staff, is that the quality process generally contributes little to the inherent worth of the services provided to customers. However, it is seen as a competitive advantage, and for this reason the overheads and costs associated with the process are recognised as a necessity".

The final lesson is that, if an organisation plans to put in place a software quality management system which has impact on the software product and service to customers, then resources, including time, must be put aside so that business functions can be incorporated into the audits and procedures required by the standard. Without a focus on producing tangible results in regard to the final product and customer service, organisations may find it very difficult to generate on-going commitment to the software quality management system.

With regard to the future of the standard itself, a number of observations can be made. It would appear that future versions of AS 3563 must allow for more scope and flexibility so that the new software development methodologies, and the wide variety of work that information technology firms perform, are taken into account. It would also appear that smaller, ad hoc, jobs need to be either exempt from having to comply with the requirements of the standard, or else be allowed to come under a "blanket" procedure to avoid individual quality plans having to be developed, which creates an administrative burden out of proportion to the jobs themselves. 


\section{REFERENCES}

Australian Information Industries Association (1993) Quality Management Issues: An IT Industry Perspective, Canberra.

Hockman, K., Grenville, R., \& Jackson, S. (1994) “Road Map to ISO 9000 Registration”, Quality Progress, Vol 27, No 5, pp 39-42.

Rouse, R., Watson, D., (1994) "The Role of Culture in Information Systems Quality", in Shanks, G., and Arnoti, D., eds. Proceedings of the 5th Australasian Conference on Information Systems, Department of Information Systems, Monash University, Caulfield East, pp 405-415.

Sakovsky, S. (1994) "Survival After ISO 9000 Registration", Quality Progress, Vol 27, No 5, pp 57-59. Srnic-Batanic, B. "[The Organisation's] System Audit Summary Table for AS 3563.1", Quality Assurance Services, South Melbourne.

Thomsett, R. (1993) People and Project Management, New York: Yourdon Press.

von Hellens, L. (1994) "Quality Management Systems in Australian Software Houses: Some Problems of Sustaining Creativity in the Software Process", in Shanks, G., and Amott, D., eds. Proceedings of the 5th Australasian Conference on Information Systems, Department of Information Systems, Monash University, Caulfield East, pp 479-492.

Zampetakis, H. (1994) "Investment in quality accreditation queried", Australian Financial Review, 31 Jan. 